\title{
Air Pollution-Regulated E-Cadherin Mediates Contact Inhibition of Proliferation via the Hippo Signaling Pathways in Emphysema
}

\section{Jer-Hwa Chang}

Taipei Medical University

Yueh-Lun Lee

Taipei Medical University

Vincent Laiman

Taipei Medical University

Chia-Li Han

Taipei Medical University

\section{Yu-Teng Jheng \\ National Taiwan University \\ Kang-Yun Lee \\ Taipei Medical University}

Chi-Tai Yeh

Taipei Medical University

Han-Pin Kuo

Taipei Medical University

Kian Fan Chung

Imperial College London

\section{Didik Setyo Heriyanto}

Gadjah Mada University: Universitas Gadjah Mada

\section{Ta-Chih Hsiao}

National Taiwan University

\section{Sheng-Ming Wu}

Taipei Medical University

Shu-Chuan Ho

Taipei Medical University

\section{Kai-Jen Chuang}

Taipei Medical University

Hsiao-Chi Chuang ( $D$ r92841005@ntu.edu.tw)

Taipei Medical University https://orcid.org/0000-0003-4651-5192 
Keywords: alveoli, COPD, emphysema, PM2.5, particulate matter, senescence.

Posted Date: June 15th, 2021

DOI: https://doi.org/10.21203/rs.3.rs-604268/v1

License: (a) (i) This work is licensed under a Creative Commons Attribution 4.0 International License. Read Full License

Version of Record: A version of this preprint was published at Chemico-Biological Interactions on November 1st, 2021. See the published version at https://doi.org/10.1016/j.cbi.2021.109763. 


\section{Abstract}

Background: Air pollution has been linked to emphysema in chronic obstruction pulmonary disease (COPD). However, the underlying mechanisms in the development of emphysema due to air pollution remain unclear. The objective of this study was to investigate the role of components of the Hippo signaling pathway for Ecadherin-mediated contact inhibition of proliferation in the lungs after air pollution exposure. E-Cadherinmediated contact inhibition of proliferation via the Hippo signaling pathway was investigated in SpragueDawley (SD) rats whole-body exposed to air pollution, and in alveolar epithelial A549 cells exposed to diesel exhaust particles (DEPs), E-cadherin-knockdown, and high-mobility group box 1 (HMGB1) treatment. Underlying epithelial differentiation, apoptosis, and senescence were also examined, and the interaction network among these proteins was examined. COPD lung sections were used to confirm the observations in rats.

Results: Expressions of HMGB1 and E-cadherin were negatively regulated in the lungs and A549 cells by air pollution, and this was confirmed by knockdown of E-cadherin and by treating A549 cells with HMGB1. Depletion of phosphorylated ( $p$ )-Yap occurred after exposure to air pollution and E-cadherin-knockdown, which resulted in decreases of SPC and T1a. Exposure to air pollution and E-cadherin-knockdown respectively downregulated p-Sirt1 and increased p53 levels in the lungs and in A549 cells. Moreover, the protein interaction network suggested that E-cadherin is a key activator in regulating Sirt1 and p53, as well as alveolar epithelial cell differentiation by SPC and T1a. Consistently, downregulation of E-cadherin, p-Yap, SPC, and T1a was observed in COPD alveolar regions with particulate matter (PM) deposition.

Conclusions: Our results indicated that E-cadherin-mediated cell-cell contact directly regulates the Hippo signaling pathway to control differentiation, cell proliferation, and senescence due to air pollution. Exposure to air pollution may initiate emphysema in COPD patients.

\section{Background}

Chronic lung diseases are important public health issues worldwide. Based on the Global Initiative for Chronic Obstructive Lung Disease (GOLD) guidelines reported in 2020, exposure to particulate matter (PM) from cigarette smoke, and occupational and air pollution is recognized as a risk factor in the development and progression of chronic obstruction pulmonary disease (COPD) [1]. PM was found to decrease lung function, and can result in COPD [2]. Epidemiological evidence has further indicated that acute exacerbation (AE) of COPD is associated with typical levels of PM of $\leq 10 \mu \mathrm{m}$ in aerodynamic diameter $\left(\mathrm{PM}_{10}\right)$ in urban areas [3]. Recently, a cohort study reported that chronic exposure to air pollution such as $\mathrm{PM}_{2.5}$ and nitrogen oxides (NOx) was associated with increased severity of emphysema according to chest computed tomography (CT) and decreasing lung function [4,5]. However, the development of emphysema due to air pollution exposure is still open to question.

When PM is inhaled into the lungs, oxidative stress, systemic inflammation, and autonomic functions are altered [6]. Pathological changes in the lungs' structure and narrowing of the small airways result from chronic inflammation due to COPD, which result in a reduction in the forced expiratory volume in $1 \mathrm{~s}\left(\mathrm{FEV}_{1}\right)$. 
Emphysema-induced parenchymal destruction contributes to airflow limitations, thereby causing oxygen desaturation [7]. Dysfunction of the repair and defense mechanisms occurs during the progression of COPD, which was reported to be caused by inflammatory responses [8]. Such inflammation-induced lung injury may lead to the development of emphysema. However, the underlying mechanisms for the development of emphysema involving air pollution remain unclear.

A recent study suggested that air pollution was associated with biological ageing in a cohort study [9]. Oxidative stress produced by air pollutants is a determinant for increasing premature senescence of endothelial cells after exposure [10]. Air pollutants caused telomere dysfunction and senescence of peripheral blood cells collected from e-waste regions in China [11]. Furthermore, alarmingly high levels of high-mobility group box 1 (HMGB1) are linked to regulation of senescence and apoptosis [12]. Those reports showed that air pollution may cause cellular senescence after exposure.

Alveolar epithelial cell type II (AECII) plays important roles in the proliferation and differentiation into alveolar epithelial cell type I (AECI). AECII synthesizes and secretes surfactants and proliferates and differentiates into $\mathrm{AECl}$ after injury in order to maintain the integrity of alveolar walls. The functions of AECIl in the Hippo signaling pathway were recently studied $[13,14]$. Yap/Taz, which are components of the Hippo signaling pathway, are transcriptional coactivators and are the main downstream mediators of the Hippo pathway. Yap was reported to regulate $\mathrm{AECll}$ functions, including AECII proliferation, differentiation into $\mathrm{AECl}$, and inflammation following lung injury [14]. Reductions in Yap/Taz resulted in an emphysematous lung phenotype of COPD $[15,16]$. However, the role of the Hippo signaling pathway in the AECIl response to air pollution is still poorly understood.

E-Cadherin mediates contact inhibition of proliferation via the Hippo signaling pathway $[17,18]$. Also, $\mathrm{PM}_{2.5}$ moderated Yap transcriptional regulation in A549 cells [19]. The objective of this study was to investigate roles of components of the Hippo signaling pathway in E-cadherin-mediated contact inhibition of proliferation in the lungs after air pollution exposure. The underlying pathways regulated by air pollution could be vital in the development of emphysema.

\section{Results}

\section{E-Cadherin depletion by air pollution-induced HMGB1}

Figure 1a shows the expressions of HMGB1 and E-cadherin in the lungs after air pollution exposure. We observed that HMGB1 in the lungs had significantly increased in the $\mathrm{PM}_{2.5}$ group $(p<0.05)$, whereas expression of E-cadherin in the lungs had significantly decreased in the high-efficiency particulate air (HEPA) and $\mathrm{PM}_{2.5}$ groups $(p<0.05)$. We further quantified E-cadherin expression in the alveolar regions of rats' lungs on IHC images. Results were consistent with the findings by Western blotting, showing that the expression of E-cadherin in alveoli had significantly decreased after air pollution exposure in the HEPA and $\mathrm{PM}_{2.5}$ groups $(p<0.05)$. We next investigated expressions of HMGB1 and E-cadherin by diesel exhaust particles (DEPs) in type II alveolar epithelial A549 cells (Fig. 1b). The level of HMGB1 significantly increased due to DEPs at 100 $\mu \mathrm{g} / \mathrm{mL}(p<0.05)$. We found significant decreases in E-cadherin due to DEPs at 50 and $100 \mu \mathrm{g} / \mathrm{mL}$ (both $p<$ 
0.05). To conform the association between HMGB1 and E-cadherin, cells were treated with $\mathrm{CDH} 1$ (Ecadherin) siRNA or HMGB1 recombinant protein. We observed that HMGB1 significantly increased after siCDH1 treatment $(p<0.05$; Fig. 1c). E-cadherin significantly decreased after HMGB1 treatment at 50 and $100 \mathrm{ng} / \mathrm{mL}$ (both $p<0.05$; Fig. 1d).

\section{Yap inactivation by air pollution-depleted E-cadherin}

We found that $\mathrm{p}$-Yap compared to total Yap (p-Yap/Yap) significantly decreased in the HEPA and $\mathrm{PM}_{2.5}$ groups (both $p<0.05$; Fig. 2a). We then quantified expressions of $p$-Yap and Yap in alveolar regions of the lungs after air pollution exposure. $\mathrm{p}-\mathrm{Yap} / \mathrm{Yap}$ ratios in alveoli significantly decreased due to air pollution exposure in the HEPA and $\mathrm{PM}_{2.5}$ groups (both $p<0.05$ ). $\mathrm{p}$-Yap/Yap ratios were significantly reduced by DEP at 50 and $100 \mu \mathrm{g} / \mathrm{mL}$ (both $p<0.05 ;$ Fig. 2b). To understand the role of E-cadherin in Yap activation, Ecadherin was knocked-down by siRNA (CDH1) in A549 cells. We observed a reduction in the p-Yap/Yap ratio that occurred after E-cadherin-knockdown ( $p<0.05$; Fig. 2c).

\section{Reduction of AECII-to-AECI differentiation by air pollution}

Figure 3a shows expressions of SPC and T1a in the lungs of rats after air pollution exposure. Both SPC and T1a significantly decreased in the HEPA and $\mathrm{PM}_{2.5}$ groups after exposure (all $p<0.05$ ). Consistently, SPC and T1a expressions in alveolar regions significantly decreased due to air pollution exposure in the HEPA and $\mathrm{PM}_{2.5}$ groups (all $p<0.05$ ). Next, the SPC level significantly decreased due to DEPs at $100 \mu \mathrm{g} / \mathrm{mL}$ ( $p<$ 0.05; Fig. 3b). We knocked-down E-cadherin to investigate the role of E-cadherin in SPC expression in A549 cells and observed a reduction of SPC by E-cadherin-knockdown in A549 cells $(p<0.05$; Fig. 3c).

\section{Senescence and apoptosis due to air pollution}

We found that $\mathrm{p}$-Sirt1 compared to total Sirt1 (p-Sirt1/Sirt1) had significantly decreased in the HEPA and $\mathrm{PM}_{2.5}$ groups (both $p<0.05$; Fig. $4 \mathrm{a}$ ). The quantified IHC results showed that $\mathrm{p}$-Sirt1/Sirt1 in alveolar regions had significantly decreased after air pollution exposure in the HEPA and $\mathrm{PM}_{2.5}$ groups (both $p<0.05$ ). Furthermore, $\mathrm{p} 53$ expression significantly increased in the HEPA and $\mathrm{PM}_{2.5}$ groups after air pollution exposure (both $p<0.05$ ). The $\mathrm{p}$-Sirt1/Sirt1 ratio was significantly reduced by DEPs at 50 and $100 \mu \mathrm{g} / \mathrm{mL}$ (both $p<0.05$; Fig. 4b), whereas p53 significantly increased due to DEP at $100 \mu \mathrm{g} / \mathrm{mL}(p<0.05)$. Next, we knocked-down E-cadherin to investigate the roles of E-cadherin in senescence and apoptosis. We observed a reduction in the p-Sirt1/Sirt1 ratio and an increase in p53 after E-cadherin-knockdown in A549 cells $(p<0.05$; Fig. 4c).

\section{Protein-Protein Interaction (PPI) network}

Interactions among these proteins in the lungs after air pollution exposure were identified and are shown in Fig. 5. Results showed that Cdh1 (E-cadherin) was the key protein in activating cellular senescence (Sirt1) and apoptosis (Tp53) as well as alveolar epithelial cell differentiation from type II (Sftpc for SPC) to type I (Pdpn for T1a). Matrix metallopeptidase (MMP)-9 was shown to be a key mediator in the Hmgb1 and E- 
cadherin interplay, which also regulated Tp53 expression. Hmgb1 regulated Sirt1 expression via heme oxygenase 1 (Hmox 1), whereas it directly regulated Tp53. On the other hand, the cytoskeletal protein, keratin 5 (Krt5), was found to be a key mediator of Cdh1 with Pdpn and Sftpc. In terms of the Hippo signaling pathway, SMAD family member 3 (Smad3) was a vital protein between Yap1 and Sirt1 or Tp53. Also, Cdh1 was a bridge for cellular differentiation of Pdpn and Sftpc.

\section{COPD and protein expressions}

Emphysema occurred in rats after 6 months of exposure to air pollution (Fig. 6a). To understand expressions of proteins examined in our study, lung sections from control and COPD animals were collected. First, we observed PM deposited in lung sections of COPD animals (Fig. 6b; red arrow). We found that expressions of E-cadherin and Yap in alveolar regions of COPD animals were lower than those in control animals (Fig. 7). Also, expressions of SPC and T1a in alveolar regions of COPD animals were lower than those in control animals.

\section{Discussion}

This is the first study to demonstrate that components of the Hippo signaling pathway are required for Ecadherin-mediated contact inhibition of proliferation in the lungs after air pollution exposure. Air pollution caused E-cadherin deletion by HMGB1; this suppressed Yap activation which triggered senescence, alveolar epithelial differentiation, and apoptosis. These protein interactions were also supported by our proteomics approach. These results provide evidence that E-cadherin hemophilic binding regulates the Hippo pathway in the lungs after air pollution exposure. Furthermore, these protein expressions in the lungs due to air pollution were consistent with emphysematous lungs of COPD patients. The underlying pathways regulated by air pollution could be vital in the development of emphysema.

The lungs are the first target organ to interact with air pollution after inhalation. Impairment of properties of the epithelial barrier is the main hallmark in the development of lung diseases, such as COPD and asthma. HMGB1 is a nuclear DNA-binding protein, which is secreted into the extracellular milieu and functions as a proinflammatory cytokine [20]. Recent reports showed that HMGB1 is involved in inflammatory lung diseases [21, 22]. Increasing permeability in the lungs due to air pollution exposure has been widely observed $[23,24]$. Our study observed that air pollution increased levels of HMGB1 in the lungs, which disrupted properties of the epithelial barrier due to deletion of E-cadherin. The association between HMGB1 and Ecadherin was further confirmed by E-cadherin-knockdown and HMGB1 treatment in A549 cells. A previous study showed that HMGB1 damaged the airway epithelial barrier due to E-cadherin deletion [25], and the impairment was further aggravated by interleukin (IL)-1 $\beta$. Collectively, air pollution exposure causes an interplay between HMGB1 and E-cadherin in the lungs. This could result in disruption of epithelial barrier properties in the lungs.

Previous reports showed that E-cadherin mediates contact inhibition of proliferation via the Hippo signaling pathway $[17,18]$. Yap and Taz, Hippo signaling pathway components, are transcriptional coactivators that are the main downstream mediators of the Hippo pathway [26]. In this study, we further showed that 
exposure to air pollution reduced E-cadherin expression and Yap phosphorylation in the lungs. Also, both exposure to DEPs and E-cadherin-knockdown in A549 cells reduced Yap phosphorylation. Depletion of Ecadherin-bound $\beta$-catenin decreased Yap phosphorylation (S127 residue) and Yap nuclear accumulation [17]. Furthermore, E-cadherin homophilic binding occurs independent of other cell interactions, and this is able to control the subcellular localization of Yap [27]. Together, our results suggest that E-cadherin is an upstream cell-surface receptor that regulates Hippo signaling pathway components, which may control alveolar epithelial differentiation and apoptosis after air pollution exposure.

Alveolar epithelial differentiation from type II to type I is not yet clear; this is how E-cadherin homophilic ligation stimulates the Hippo pathway after air pollution exposure. Type II alveolar epithelial cells are considered to be progenitor cells involved in regenerative processes [28] via the Hippo signaling pathway [13, 14]. When the Hippo pathway is inhibited, Yap/Taz are able to accumulate in nuclei. The accumulated Yap/Taz interact with transcription factors and activate gene expressions, thereby activating cell survival, proliferation, and differentiation pathways [29]. A previous report showed that inactivation of E-cadherin and a-catenin affected bronchiolar progenitor cell differentiation and airway regeneration [38]. Indeed, we observed significant reductions in SPC and T1a in the lungs after air pollution exposure. Our results suggest that the pathway for type II-to-type I alveolar epithelial differentiation is impaired by chronic exposure to air pollution. Also, numbers of these epithelial cells were decreased by air pollution. Thus, air pollution is involved in regulating the Hippo signaling pathway which affects AECIl activities and could lead to alterations in its proliferation.

Cellular senescence is a state of permanent inhibition of cell proliferation, which is associated with COPD [30]. We observed that air pollution exposure reduced Sirt1 phosphorylation in the lungs. Also, both exposure to DEPs and E-cadherin-knockdown in A549 cells caused a decrease in Sirt1 phosphorylation. Air pollution induces senescence by regulating Sirt1 as observed in vitro [31] and in vivo [32]. Senescent cells were shown to secrete a senescence-associated secretory phenotype (SASP). HMGB1 is linked to regulation of cell senescence, which is considered a mediator of cellular senescent responses [33, 34]. Alveolar epithelial cell senescence was reported in COPD patients [35], which may explain the abnormal cell turnover that promotes the loss of alveolar cells in emphysematous lungs.

Apoptosis and senescence are cellular responses to a variety of intrinsic and extrinsic signals. In contrast to apoptosis, cellular senescence is the loss of proliferative capacity. Our results indicated that apoptosis via p53 expression occurred due to air pollution exposure, which was confirmed by DEP exposure and Ecadherin-knockdown in A549 cells. Previous reports indicated that p53 is required for PM-induced apoptosis of alveolar epithelial cells [36, 37]. Increased levels of apoptosis in alveolar epithelia lead to emphysematous changes in the lungs $[38,39]$. Recent studies showed that emphysema is associated with disruption of functions of alveolar apoptosis and cell proliferation [38]. Not only is apoptosis activated by air pollution, but we also found cellular senescence by Sirt 1 phosphorylation in the lungs and in A549 cells. These results suggest that air pollution disables the proliferative capacity of lung cells. Regulation of both apoptosis and senescence was associated with E-cadherin expression according to results of E-cadherin-knockdown in A549 cells. Therefore, air pollution can cause apoptosis and cellular senescence, and this could occur by Ecadherin mediating contact inhibition of proliferation via the Hippo signaling pathway. 
The PPI network was examined in the lungs using proteomic analyses. We confirmed that E-cadherin plays an essential role in activating the Hippo signaling pathway and regulating cell apoptosis, senescence, and differentiation of ACEll to ACEI due to air pollution. First, we found that MMP-9 was involved in regulation between HMGB1 and E-cadherin. This finding showed that air pollution can induce the epithelial-tomesenchymal transition (EMT) by HMGB1 expression. A previous study observed that HMGB1 induced the EMT by downregulating Cdh1 gene expression in human airway epithelial cells [40]. This was confirmed by our results, in which E-cadherin regulated apoptosis and senescence due to air pollution. Notably, cellular differentiation from $\mathrm{AECll}$ to $\mathrm{AECl}$ was regulated via $\mathrm{Krt} 5$ from E-cadherin. Another report identified that SPC and $\mathrm{Krt} 5$ were in airway and alveolar cells in lung disease, indicating that alternative progenitor lineages are mobilized to regenerate the alveolar epithelium when AECII is severely injured [41]. The Hippo signaling pathway component, Yap, was identified to regulate apoptosis and senescence via Smad3 in this study. This result suggests that the Hippo pathway is not only essential to cell death and proliferation due to air pollution, but also important for the EMT.

We observed that unconcentrated ambient air pollution exposure in rats for 6 months caused significant emphysema. This observation was also reported by our previous study [42]. We further investigated these protein expressions in alveolar regions of control and COPD subjects. Notably, we found that PM had been deposited in COPD lungs, but not in control subjects. We suspect that inhaled PM is more easily deposited or trapped in the lungs due to a reduction in lung functions due to COPD severity. One study showed that higher fractions of PM from cigarette smoke were deposited in the last few airway generations [43]. The deposited PM in the lower airway and alveolar regions may be associated with the development of emphysema. However, more evidence is required to confirm the possible causal relationship.

We observed that expressions of E-cadherin with Yap, and SPC with T1区 in alveolar regions of COPD subjects obviously decreased compared to those regions of control subjects. This observation is consistent with results in rats after air pollution exposure. Previous reports indicated that selective loss of Yap in restricted regions of the mouse lung epithelium leads to lung cysts that mimic emphysema [16]. Additionally, a Taz deficiency resulted in lung developmental abnormalities in mice, which led to an emphysematous lung phenotype [15]. Collectively, air pollution regulates E-cadherin which mediates contact inhibition of proliferation via the Hippo signaling pathway in emphysema.

There are some limitations of this study that should be noted. Chemical effects of air pollution on the Hippo signaling pathway were not examined in this study, and should be determined in the future. Primary AECII should be used to understand the ability of differentiation to ACEl by air pollution. The role of the air pollution-induced EMT should be further investigated. Confirmatory experiments linked to air pollution should be conducted in humans.

\section{Conclusions}

In summary, our findings provide evidence that air pollution is involved in regulating E-cadherin which mediates contact inhibition of proliferation via the Hippo signaling pathway in the lungs. Dysfunction of the differentiation and proliferation of AECII by air pollution could be vital to the development of emphysema. 
Our study provides novel insights into a better understanding of the underlying mechanisms for air pollutioninduced emphysema.

\section{Materials And Methods}

\section{Ethics and human lung samples}

The study was approved by the Taipei Medical University-Joint Institutional Review Board (TMU-JIRB no. N202003075). Lung function was measured before lung cancer surgery. A pulmonary function test with a spirometer was conducted immediately before bronchoscopy and included parameters of the forced vital capacity $(F V C)$ and $\mathrm{FEV}_{1}$. Lung tissues were obtained from subjects undergoing peripheral lung tumor removal. Control and COPD lung sections were derived from non-tumorous lesion segments. Lung sections were used for examination of protein expressions between control and COPD subjects.

\section{Animals}

Six-month old male Sprague Dawley (SD) rats (National Laboratory Animal Center, Taipei, Taiwan) were housed at a constant temperature of $22 \pm 2{ }^{\circ} \mathrm{C}$ and a relative humidity $(\mathrm{RH})$ of $55 \% \pm 10 \%$ with a $12: 12-\mathrm{h}$ light: dark cycle. This study was conducted in compliance with the Animal and Ethics Review Committee of the Laboratory Animal Center at Taipei Medical University (Taipei, Taiwan; IACUC: LAC2015-0290).

\section{Chronic exposure to air pollution in vivo}

Rats were randomly assigned to three groups: a control group, a HEPA group, and a $\mathrm{PM}_{2.5}$ group ( $n=8$ in each group). The whole-body exposure system to air pollution for rodents was previously reported $[44,45]$. Unconcentrated ambient particulate pollution with a 2.5- $\mu \mathrm{m}$ particle size classifier was introduced to the whole-body exposure system with or without HEPA filtration (which had a 99\% particle-removal efficiency) at the front of the airflow inlet [46]. Rats were exposed to HEPA-filtered air (so were only exposed to gaseous pollution) and $\mathrm{PM}_{2.5}$ for 6 months. Simultaneously, rats in the control group were housed in the Laboratory Animal Center with HEPA-filtered clean air for 6 months. Rats were exposed to an average of $16.3 \mu \mathrm{g} / \mathrm{m}^{3}$ $\mathrm{PM}_{2.5}, 32.9 \mathrm{ppb} \mathrm{NOx}, 2.5 \mathrm{ppb} \mathrm{SO}_{2}$, and $29.7 \mathrm{ppb} \mathrm{O}$ during the 6 months [47]. After exposure for 6 months, rats were euthanized, and lung tissues were collected.

\section{Cell culture and treatment}

Human lung alveolar epithelial type II A549 cells were obtained from the American Type Culture Collection (ATCC, Manassas, VA, USA), and were cultured in RPMI medium containing 10\% fetal bovine serum, penicillin, and streptomycin at $37{ }^{\circ} \mathrm{C}$ with $95 \%$ humidity and $5 \% \mathrm{CO}_{2}$. Standard Reference Material DEPs obtained from the National Institute of Standards and Technology (NIST, Gaithersburg, MD, USA) were used as surrogate particles for traffic emissions. Cells were exposed to DEPs at 0 (control), 50 , and $100 \mu \mathrm{g} / \mathrm{mL}$ for $24 \mathrm{~h}$ ( $n=6$ per group). Cells were treated with the HMBG1 recombinant protein (Sigma, St. Louis, MO, USA) at 0 (control), 50 , and $100 \mathrm{ng} / \mathrm{mL}$ for $24 \mathrm{~h}$. All experiments were conducted at cell viabilities of $>80 \%$.

\section{E-Cadherin-knockdown}


Transfection of E-cadherin small interfering (si)RNA (CDH1; ThermoFisher Scientific, Waltham, MA, USA) and Lipofectamine 3000 reagent (ThermoFisher Scientific) into cells was conducted in accordance with the manufacturer's instructions. Culture medium in each well was supplemented with $50 \mathrm{nM}$ of CDH1 siRNA or a negative siRNA control vector (with no homology in human, mouse, or rat messenger ( $m$ )RNA databases; sense: GAUCAUACGUGCGAUCAGA dTdT; antisense: UCUGAUCGCACGUAUGAUC dTdT). At $24 \mathrm{~h}$ after siRNA transfection, supernatants and cell lysates were collected for further analyses. Transfection details were previously reported [48].

\section{Western blotting}

Preparation of tissue and cell lysates was previously reported [44, 47, 49]. Lysate samples were electrotransferred onto polyvinylidene difluoride membranes (Millipore, Darmstadt, Germany). Primary antibodies for HMGB1 (1:1000), E-cadherin (1:1000), Yap (1:1000), phosphorylated (p)-Yap (1:1000), SPC (1:1000), T1a (podoplanin; 1:1000), Sirt1 (1:1000), p-Sirt1 (1:1000), p53 (1:1000) $\beta$-actin (1:1000), and atubulin (1:1000) were obtained from Cell Signaling (Danvers, MA, USA) or Abcam (USA). Anti-rabbit (1:2000) horseradish peroxidase (HRP)-conjugated secondary antibodies were obtained from Chemicon International (MA, USA) and Merck Millipore (MA, USA). An HRP-labeled secondary antibody was incubated and washed with TBST after blocking. Enhanced chemiluminescence Western blotting reagents were used, after which images were taken with a ChemiDoc MP imager (Bio-Rad, Hercules, CA, USA). Quantitative data were obtained using Image-Pro vers. 4 (Media Cybernetics, MD, USA) for Windows. All data were adjusted to the control (multiples of change of the control) as previously reported [50, 51].

\section{Immunohistochemical (IHC) and immunofluorescent (IF) staining}

Lung tissues were fixed in $4 \%$ paraformaldehyde (Sigma) at $25 \mathrm{cmH}_{2} \mathrm{O}$ and in $70 \%$ ethanol $\left(4^{\circ} \mathrm{C}\right)$. Tissues were then treated with graded ethanol and xylene series before being embedded in paraffin. Paraffinembedded lung tissues were sectioned at $4 \mu \mathrm{m}$ onto charged slides using a rotary microtome. IHC staining was performed on lung sections using the Novolink Polymer Detection System (Novolink, Novocastra, Newcastle, UK) as previously described [52]. Lung sections were incubated with antibodies against Ecadherin (AB40772, Abcam), p-Yap (AB76252, Abcam), Yap (66900-1-Ig, Proteintech, USA), SPC (\#32459, SAB, USA), T1a (AB131216, Abcam), and Sirt1 (\#9475, Cell Signaling). Microphotographs were acquired using Motic Easyscan Pro and Motic DSAssistant software (Motic, Hong Kong, China). The semiquantitative determination of protein expression was assessed in 10 non-overlapping fields as previously described [52]. Lung sections for IF staining were processed in the same way as IHC until the antigen retrieval step. Lung sections were then permeabilized using $0.25 \%$ Triton X-100 in phosphate-buffered saline (PBS). The blocking step was performed using a $5 \%$ bovine serum albumin (BSA) solution. Rabbit anti-E-cadherin (AB40772, Abcam), mouse anti-Yap (66900-1-Ig, Proteintech), FITC-conjugated SPC (bs-10067R-FITC, Bioss, USA), and FITC-conjugated T1a (orb215007-CF594, Biorbyt, UK) were used to incubate lung sections. FITC-conjugated species-specific secondary antibodies (AB150077 and AB150116, Abcam) were used for IF staining, and 4',6diamidino-2-phenylindole (DAPI) (AB104139, Abcam) was used for nuclear staining. Fluorescent images were captured using a confocal fluorescence microscope (TCS SP5, Leica, UK).

\section{Quantitative tissue proteomics analysis}


Experimental details were reported in our previous study [53]. In brief, lung tissues were lysed and homogenized using a Minilys ${ }^{\circledR}$ personal homogenizer (Bertin, Rockville, MD, USA) to collect clear supernatants as lung tissue lysates. Fifty micrograms of lung tissue proteins from five randomly selected rats in each group was separately subjected to gel-assisted digestion with trypsin [54], and resulting peptides from the same exposure group were pooled and labeled with one of the tandem mass tag isobaric reagents (ThermoFisher Scientific). Labeled peptides were then pooled and fractionated by reverse-phase StageTip following a previously reported protocol [55]. Each peptide fraction was vacuum-dried and resuspended in $0.1 \%$ formic acid for the liquid chromatography (LC)-tandem mass spectrometric (MS/MS) analysis using a Thermo UltiMate 3000 RSLCnano system connected to an Orbitrap Fusion ${ }^{T M}$ Tribrid $^{\text {TM }}$ Mass Spectrometer (ThermoFisher Scientific, Bremen, Germany) equipped with a nanospray interface (New Objective, Woburn, MA, USA). The LC-MS/MS raw data were searched against the SwissProt Rattus norvegicus database (vers. 2018_11, 8054 entries) using Mascot implemented in Proteome Discoverer (vers. 2.2.0.388, ThermoFisher). A false discovery rate of $1 \%$ was applied to peptide-spectral-match, peptide, and protein levels. For proteome quantification, only unique peptides identified with high confidence and with at least six amino acids were included to estimate protein abundances, which were further normalized by the total peptide abundance. Proteins with 1.3-fold changes in abundance ( $\log 2$ ratio of $>0.38$ or $<-0.38$ ) were considered differentially expressed proteins. The protein-protein interacting (PPI) network was built for differentially expressed proteins using the STRING database [56] implemented in Cytoscape software [57].

\section{Statistical analysis}

Data are expressed as the mean \pm standard deviation (SD). Student's $t$-test was used for comparisons between continuous variables. For comparisons among multiple values, a one-way analysis of variance (ANOVA) with Tukey's post-hoc test was used. Statistical analyses were performed using GraphPad vers. 5 for Windows. The level of significance was set to $p<0.05$.

\section{Declarations}

\section{Ethical Approval and Consent to participate}

The study was approved by the Taipei Medical University-Joint Institutional Review Board (TMU-JIRB no. N202003075).

All the animal protocols were prepared in accordance with the Guide for the Care and Use of Laboratory Animals and were approved by the Laboratory Animal Center at National Taiwan University (Taipei, Taiwan).

\section{Consent for publication}

Not applicable.

\section{Availability of supporting data}


The datasets used and/or analyzed during the current study are available from the corresponding author on reasonable request.

\section{Competing interests}

The authors declare that they have no conflicts of interest.

\section{Funding}

This study was funded by the Ministry of Science and Technology of Taiwan (108-2314-B-038-093 and 1092314-B-038-093-MY3).

\section{Authors' contributions}

All authors contributed substantially to the concept and design of the study, drafting of the article, and critically revising the manuscript for important intellectual content. All authors have read and approved the final version of the manuscript for publication.

\section{Acknowledgements}

The authors wish to thank Yi-Syuan Lin for technical assistance with this research. KF Chung is a Visiting Professor at Taipei Medical University.

\section{Authors' information}

${ }^{1}$ School of Respiratory Therapy, College of Medicine, Taipei Medical University, Taipei, Taiwan. ${ }^{2}$ Division of Pulmonary Medicine, Department of Internal Medicine, Wan Fang Hospital, Taipei Medical University, Taipei, Taiwan. ${ }^{3}$ Department of Microbiology and Immunology, School of Medicine, College of Medicine, Taipei Medical University, Taipei, Taiwan. ${ }^{4}$ International PhD Program in Medicine, College of Medicine, Taipei Medical University, Taipei, Taiwan. ${ }^{5}$ Department of Anatomical Pathology, Faculty of Medicine, Public Health, and Nursing, Universitas Gadjah Mada, Yogyakarta, Indonesia. ${ }^{6}$ Master Program in Clinical Pharmacogenomics and Pharmacoproteomics, College of Pharmacy, Taipei Medical University, Taipei, Taiwan. ${ }^{7}$ Genome and Systems Biology Degree Program, Academia Sinica and National Taiwan University, Taipei, Taiwan. ${ }^{8}$ Division of Pulmonary Medicine, Department of Internal Medicine, School of Medicine, College of Medicine, Taipei Medical University, Taipei, Taiwan. ${ }^{9}$ Division of Pulmonary Medicine, Department of Internal Medicine, Shuang Ho Hospital, Taipei Medical University, New Taipei City, Taiwan. ${ }^{10}$ Department of Medical Research \& Education, Shuang Ho Hospital, Taipei Medical University, New Taipei City, Taiwan. ${ }^{11}$ National Heart and Lung Institute, Imperial College London, London, UK. ${ }^{12}$ Graduate Institute of Environmental Engineering, National Taiwan University, Taipei, Taiwan. ${ }^{13}$ School of Public Health, College of 
Public Health, Taipei Medical University, Taipei, Taiwan. ${ }^{14}$ Department of Public Health, School of Medicine, College of Medicine, Taipei Medical University, Taipei, Taiwan. ${ }^{15}$ Cell Physiology and Molecular Image Research Center, Wan Fang Hospital, Taipei Medical University, Taipei, Taiwan.

\section{References}

1. Global Initiative for Chronic Obstructive Lung Disease: Global Strategy for Prevention, Diagnosis and Management of COPD (2020 report). 2020.

2. Schikowski T, Mills IC, Anderson HR, Cohen A, Hansell A, Kauffmann F, et al. Ambient air pollution- a cause for COPD? Eur Respir J. 2013; doi: 10.1183/09031936.00100112. http://www.ncbi.nlm.nih.gov/pubmed/23471349.

3. Kumar N, Liang D, Comellas A, Chu AD, Abrams T. Satellite-based PM concentrations and their application to COPD in Cleveland, $\mathrm{OH}$. Journal of exposure science \& environmental epidemiology. 2013;23 6:637 - 46; doi: 10.1038/jes.2013.52. http://www.ncbi.nlm.nih.gov/pubmed/24045428.

4. Wang M, Aaron CP, Madrigano J, Hoffman EA, Angelini E, Yang J, et al. Association Between Long-term Exposure to Ambient Air Pollution and Change in Quantitatively Assessed Emphysema and Lung Function. JAMA : the journal of the American Medical Association. 2019;322 6:546 - 56; doi: 10.1001/jama.2019.10255. https://www.ncbi.nlm.nih.gov/pubmed/31408135.

5. Adar SD, Kaufman JD, Diez-Roux AV, Hoffman EA, D'Souza J, Stukovsky KH, et al. Air pollution and percent emphysema identified by computed tomography in the Multi-Ethnic study of Atherosclerosis. Environ Health Perspect. 2015;123 2:144 - 51; doi: 10.1289/ehp.1307951.

6. Brook RD, Rajagopalan S, Pope CA, 3rd, Brook JR, Bhatnagar A, Diez-Roux AV, et al. Particulate matter air pollution and cardiovascular disease: An update to the scientific statement from the American Heart Association. Circulation. 2010;121 21:2331-78; doi: 10.1161/CIR.0b013e3181dbece1. https://www.ncbi.nlm.nih.gov/pubmed/20458016.

7. Hogg JC, Chu F, Utokaparch S, Woods R, Elliott WM, Buzatu L, et al. The nature of small-airway obstruction in chronic obstructive pulmonary disease. The New England journal of medicine. 2004;350 26:2645-53; doi: 10.1056/NEJMoa032158. http://www.ncbi.nlm.nih.gov/pubmed/15215480.

8. O'Donnell R, Breen D, Wilson S, Djukanovic R. Inflammatory cells in the airways in COPD. Thorax. 2006;61 5:448 - 54; doi: 10.1136/thx.2004.024463. https://www.ncbi.nlm.nih.gov/pubmed/16648353.

9. Ward-Caviness CK, Nwanaji-Enwerem JC, Wolf K, Wahl S, Colicino E, Trevisi L, et al. Long-term exposure to air pollution is associated with biological aging. Oncotarget. 2016;7 46:74510-25; doi:

10.18632/oncotarget.12903. https://www.ncbi.nlm.nih.gov/pubmed/27793020.

10. Sharma K, Lee HH, Gong DS, Park SH, Yi E, Schini-Kerth V, et al. Fine air pollution particles induce endothelial senescence via redox-sensitive activation of local angiotensin system. Environ Pollut. 2019;252 Pt A:317 - 29; doi: 10.1016/j.envpol.2019.05.066. https://www.ncbi.nlm.nih.gov/pubmed/31158660.

11. Yuan J, Liu Y, Wang J, Zhao Y, Li K, Jing Y, et al. Long-term Persistent Organic Pollutants Exposure Induced Telomere Dysfunction and Senescence-Associated Secretary Phenotype. J Gerontol A Biol Sci 
Med Sci. 2018;73 8:1027-35; doi: 10.1093/gerona/gly002.

https://www.ncbi.nlm.nih.gov/pubmed/29360938.

12. Lee JJ, Park IH, Rhee WJ, Kim HS, Shin JS. HMGB1 modulates the balance between senescence and apoptosis in response to genotoxic stress. FASEB journal : official publication of the Federation of American Societies for Experimental Biology. 2019;33 10:10942-53; doi: 10.1096/fj.201900288R. https://www.ncbi.nlm.nih.gov/pubmed/31284735.

13. Sun T, Huang Z, Zhang H, Posner C, Jia G, Ramalingam TR, et al. TAZ is required for lung alveolar epithelial cell differentiation after injury. JCI Insight. 2019;5 14; doi: 10.1172/jci.insight.128674.

14. LaCanna R, Liccardo D, Zhang P, Tragesser L, Wang Y, Cao T, et al. Yap/Taz regulate alveolar regeneration and resolution of lung inflammation. The Journal of clinical investigation. 2019;129 5:2107-22; doi: 10.1172/JCl125014. https://www.ncbi.nlm.nih.gov/pubmed/30985294.

15. Mitani A, Nagase T, Fukuchi K, Aburatani H, Makita R, Kurihara H. Transcriptional coactivator with PDZbinding motif is essential for normal alveolarization in mice. Am J Respir Crit Care Med. 2009;180 4:326 - 38; doi: 10.1164/rccm.200812-18270C. https://www.ncbi.nlm.nih.gov/pubmed/19498055.

16. Lin C, Yao E, Zhang K, Jiang X, Croll S, Thompson-Peer K, et al. YAP is essential for mechanical force production and epithelial cell proliferation during lung branching morphogenesis. Elife. 2017;6; doi: 10.7554/eLife.21130. https://www.ncbi.nlm.nih.gov/pubmed/28323616.

17. Kim NG, Koh E, Chen X, Gumbiner BM. E-cadherin mediates contact inhibition of proliferation through Hippo signaling-pathway components. Proceedings of the National Academy of Sciences of the United States of America. 2011;108 29:11930-5; doi: 10.1073/pnas.1103345108.

18. Tsuneki M, Madri JA. Adhesion molecule-mediated hippo pathway modulates hemangioendothelioma cell behavior. Molecular and cellular biology. 2014;34 24:4485-99; doi: 10.1128/mcb.00671-14.

19. Gao R, Yun Y, Cai Z, Sang N. PM2.5-associated nitro-PAH exposure promotes tumor cell metastasis through Hippo-YAP mediated transcriptional regulation. Sci Total Environ. 2019;678:611-7; doi: 10.1016/j.scitotenv.2019.04.420. https://www.ncbi.nlm.nih.gov/pubmed/31078851.

20. Castiglioni A, Canti V, Rovere-Querini P, Manfredi AA. High-mobility group box 1 (HMGB1) as a master regulator of innate immunity. Cell Tissue Res. 2011;343 1:189 - 99; doi: 10.1007/s00441-010-1033-1.

21. Kanazawa H, Tochino Y, Asai K, Ichimaru Y, Watanabe T, Hirata K. Validity of HMGB1 measurement in epithelial lining fluid in patients with COPD. Eur J Clin Invest. 2012;42 4:419 - 26; doi: 10.1111/j.13652362.2011.02598.x.

22. Shim EJ, Chun E, Lee HS, Bang BR, Kim TW, Cho SH, et al. The role of high-mobility group box-1 (HMGB1) in the pathogenesis of asthma. Clinical and experimental allergy : journal of the British Society for Allergy and Clinical Immunology. 2012;42 6:958 - 65; doi: 10.1111/j.1365-2222.2012.03998.x.

23. Wang T, Wang L, Moreno-Vinasco L, Lang GD, Siegler JH, Mathew B, et al. Particulate matter air pollution disrupts endothelial cell barrier via calpain-mediated tight junction protein degradation. Part Fibre Toxicol. 2012;9:35; doi: 10.1186/1743-8977-9-35.

24. Wang T, Wang L, Zaidi SR, Sammani S, Siegler J, Moreno-Vinasco L, et al. Hydrogen sulfide attenuates particulate matter-induced human lung endothelial barrier disruption via combined reactive oxygen 
species scavenging and Akt activation. American journal of respiratory cell and molecular biology. 2012;47 4:491-6; doi: 10.1165/rcmb.2011-02480C.

25. Huang W, Zhao H, Dong H, Wu Y, Yao L, Zou F, et al. High-mobility group box 1 impairs airway epithelial barrier function through the activation of the RAGE/ERK pathway. International journal of molecular medicine. 2016;37 5:1189-98; doi: 10.3892/ijmm.2016.2537.

https://pubmed.ncbi.nlm.nih.gov/27035254 https://www.ncbi.nlm.nih.gov/pmc/articles/PMC4829140/.

26. Hong W, Guan KL. The YAP and TAZ transcription co-activators: key downstream effectors of the mammalian Hippo pathway. Semin Cell Dev Biol. 2012;23 7:785 - 93; doi:

10.1016/j.semcdb.2012.05.004. https://www.ncbi.nlm.nih.gov/pubmed/22659496.

27. Mendonsa AM, Na T-Y, Gumbiner BM. E-cadherin in contact inhibition and cancer. Oncogene. 2018;37 35:4769-80; doi: 10.1038/s41388-018-0304-2. https://doi.org/10.1038/s41388-018-0304-2.

28. Hogan BL, Barkauskas CE, Chapman HA, Epstein JA, Jain R, Hsia CC, et al. Repair and regeneration of the respiratory system: complexity, plasticity, and mechanisms of lung stem cell function. Cell Stem Cell. 2014;15 2:123 - 38; doi: 10.1016/j.stem.2014.07.012.

https://www.ncbi.nlm.nih.gov/pubmed/25105578.

29. Yu FX, Guan KL. The Hippo pathway: regulators and regulations. Genes \& development. 2013;27 4:355 - 71; doi: 10.1101/gad.210773.112. https://www.ncbi.nlm.nih.gov/pubmed/23431053.

30. Kuwano K, Araya J, Hara H, Minagawa S, Takasaka N, Ito S, et al. Cellular senescence and autophagy in the pathogenesis of chronic obstructive pulmonary disease (COPD) and idiopathic pulmonary fibrosis (IPF). Respiratory investigation. 2016;54 6:397-406; doi: 10.1016/j.resinv.2016.03.010. https://www.ncbi.nlm.nih.gov/pubmed/27886850.

31. Tien CP, Chen CH, Lin WY, Liu CS, Liu KJ, Hsiao M, et al. Ambient particulate matter attenuates Sirtuin1 and augments SREBP1-PIR axis to induce human pulmonary fibroblast inflammation: molecular mechanism of microenvironment associated with COPD. Aging. 2019;11 13:4654-71; doi: 10.18632/aging.102077.

32. Ribeiro Júnior G, de Souza Xavier Costa N, Belotti L, Dos Santos Alemany AA, Amato-Lourenço LF, da Cunha PG, et al. Diesel exhaust exposure intensifies inflammatory and structural changes associated with lung aging in mice. Ecotoxicol Environ Saf. 2019;170:314 - 23; doi: 10.1016/j.ecoenv.2018.11.139.

33. Davalos AR, Kawahara M, Malhotra GK, Schaum N, Huang J, Ved U, et al. p53-dependent release of Alarmin HMGB1 is a central mediator of senescent phenotypes. The Journal of cell biology. 2013;201 4:613 - 29; doi: 10.1083/jcb.201206006. https://www.ncbi.nlm.nih.gov/pubmed/23649808.

34. Parikh P, Wicher S, Khandalavala K, Pabelick CM, Britt RD, Jr., Prakash YS. Cellular senescence in the lung across the age spectrum. Am J Physiol Lung Cell Mol Physiol. 2019;316 5:L826-L42; doi: 10.1152/ajplung.00424.2018. https://www.ncbi.nlm.nih.gov/pubmed/30785345.

35. Tsuji T, Aoshiba K, Nagai A. Alveolar cell senescence in patients with pulmonary emphysema. Am J Respir Crit Care Med. 2006;174 8:886 - 93; doi: 10.1164/rccm.200509-13740C. https://www.ncbi.nlm.nih.gov/pubmed/16888288.

36. Soberanes S, Panduri V, Mutlu GM, Ghio A, Bundinger GR, Kamp DW. p53 mediates particulate matterinduced alveolar epithelial cell mitochondria-regulated apoptosis. Am J Respir Crit Care Med. 2006;174 
11:1229-38; doi: 10.1164/rccm.200602-2030C.

37. Urich D, Soberanes S, Burgess Z, Chiarella SE, Ghio AJ, Ridge KM, et al. Proapoptotic Noxa is required for particulate matter-induced cell death and lung inflammation. FASEB journal : official publication of the Federation of American Societies for Experimental Biology. 2009;23 7:2055-64; doi: 10.1096/fj.08114546.

38. Yokohori N, Aoshiba K, Nagai A, Respiratory Failure Research Group in J. Increased levels of cell death and proliferation in alveolar wall cells in patients with pulmonary emphysema. Chest. 2004;125 2:626 32; doi: 10.1378/chest.125.2.626. https://www.ncbi.nlm.nih.gov/pubmed/14769747.

39. Imai K, Mercer BA, Schulman LL, Sonett JR, D'Armiento JM. Correlation of lung surface area to apoptosis and proliferation in human emphysema. Eur Respir J. 2005;25 2:250-8; doi:

10.1183/09031936.05.00023704. https://www.ncbi.nlm.nih.gov/pubmed/15684288.

40. Chen YC, Statt S, Wu R, Chang HT, Liao JW, Wang CN, et al. High mobility group box 1-induced epithelial mesenchymal transition in human airway epithelial cells. Sci Rep. 2016;6:18815; doi: 10.1038/srep18815.

41. Yee M, Domm W, Gelein R, Bentley KL, Kottmann RM, Sime PJ, et al. Alternative Progenitor Lineages Regenerate the Adult Lung Depleted of Alveolar Epithelial Type 2 Cells. American journal of respiratory cell and molecular biology. 2017;56 4:453 - 64; doi: 10.1165/rcmb.2016-01500C.

42. Chuang HC, Chen YY, Hsiao TC, Chou HC, Kuo HP, Feng PH, et al. Alteration in angiotensin-converting enzyme 2 by PM(1) during the development of emphysema in rats. ERJ Open Res. 2020;6 4; doi: 10.1183/23120541.00174-2020.

43. Nicolaou L, Checkley W. Differences between cigarette smoking and biomass smoke exposure: An in silico comparative assessment of particulate deposition in the lungs. Environ Res. 2021;197:111116; doi: 10.1016/j.envres.2021.111116.

44. Chuang HC, Chen HC, Chai PJ, Liao HT, Wu CF, Chen CL, et al. Neuropathology changed by 3- and 6months low-level PM(2.5) inhalation exposure in spontaneously hypertensive rats. Part Fibre Toxicol. 2020;17 1:59; doi: 10.1186/s12989-020-00388-6.

45. Shih C-H, Chen J-K, Kuo L-W, Cho K-H, Hsiao T-C, Lin Z-W, et al. Chronic pulmonary exposure to trafficrelated fine particulate matter causes brain impairment in adult rats. Part Fibre Toxicol. 2018;245:226 34.

46. Hsiao TC, Chang J, Wang JY, Wu D, Chuang KJ, Chen JK, et al. Serum Neurofilament Light Polypeptide is a Biomarker for Inflammation in Cerebrospinal Fluid Caused by Fine Particulate Matter. Aerosol Air Qual Res. 2020;20:1665-74; doi: https://doi.org/10.4209/aaqr.2019.08.0376.

47. Chuang $\mathrm{H}-\mathrm{C}$, Chen $\mathrm{Y}-\mathrm{Y}$, Hsiao T-C, Chou H-C, Kuo H-P, Feng P-H, et al. Alteration in angiotensin-converting enzyme 2 by PM1 during the development of emphysema in rats. ERJ Open Research. 2020.

48. Lin CH, Cheng HW, Hsu MJ, Chen MC, Lin CC, Chen BC. c-Src mediates thrombin-induced NF-kappaB activation and IL-8/CXCL8 expression in lung epithelial cells. J Immunol. 2006;177 5:3427-38; doi: 10.4049/jimmunol.177.5.3427.

49. Lai CH, Lee CN, Bai KJ, Yang YL, Chuang KJ, Wu SM, et al. Protein oxidation and degradation caused by particulate matter. Sci Rep. 2016;6:33727; doi: 10.1038/srep33727. 
https://www.ncbi.nlm.nih.gov/pubmed/27644844.

50. Chen BC, Chang YS, Kang JC, Hsu MJ, Sheu JR, Chen TL, et al. Peptidoglycan induces nuclear factorkappaB activation and cyclooxygenase-2 expression via Ras, Raf-1, and ERK in RAW 264.7 macrophages. J Biol Chem. 2004;279 20:20889-97; doi: 10.1074/jbc.M311279200. http://www.ncbi.nlm.nih.gov/pubmed/15007072.

51. Bai KJ, Chuang KJ, Chen CL, Jhan MK, Hsiao TC, Cheng TJ, et al. Microglial activation and inflammation caused by traffic-related particulate matter. Chemico-biological interactions. 2019;311:108762; doi: 10.1016/j.cbi.2019.108762. https://www.ncbi.nlm.nih.gov/pubmed/31348917.

52. Crowe AR, Yue W. Semi-quantitative Determination of Protein Expression using Immunohistochemistry Staining and Analysis: An Integrated Protocol. Bio Protoc. 2019;9 24; doi: 10.21769/BioProtoc.3465.

53. Yu-Teng J, Denise Utami P, Hsiao-Chi C, Kang-Yun L, Hsiu-Chu C, San-Yuan W, et al. Particle and Fibre Toxicology. 2021; doi: 10.21203/rs.3.rs-40838/v2. https://doi.org/10.21203/rs.3.rs-40838/v2.

54. Putri DU, Feng PH, Hsu YH, Lee KY, Jiang FW, Kuo LW, et al. Chemotherapy Immunophenoprofiles in NonSmall-Cell Lung Cancer by Personalized Membrane Proteomics. Proteomics Clin Appl. 2018;12 2; doi: 10.1002/prca.201700040. https://www.ncbi.nlm.nih.gov/pubmed/29278294.

55. Rappsilber J, Mann M, Ishihama Y. Protocol for micro-purification, enrichment, pre-fractionation and storage of peptides for proteomics using StageTips. Nat Protoc. 2007;2 8:1896 - 906; doi: 10.1038/nprot.2007.261. https://www.ncbi.nlm.nih.gov/pubmed/17703201 https://www.nature.com/articles/nprot.2007.261.

56. Szklarczyk D, Gable AL, Lyon D, Junge A, Wyder S, Huerta-Cepas J, et al. STRING v11: protein-protein association networks with increased coverage, supporting functional discovery in genome-wide experimental datasets. Nucleic Acids Res. 2019;47 D1:D607-D13; doi: 10.1093/nar/gky1131. https://www.ncbi.nlm.nih.gov/pubmed/30476243.

57. Shannon P, Markiel A, Ozier O, Baliga NS, Wang JT, Ramage D, et al. Cytoscape: a software environment for integrated models of biomolecular interaction networks. Genome Res. 2003;13 11:2498 - 504; doi: 10.1101/gr.1239303. https://www.ncbi.nlm.nih.gov/pubmed/14597658.

\section{Figures}



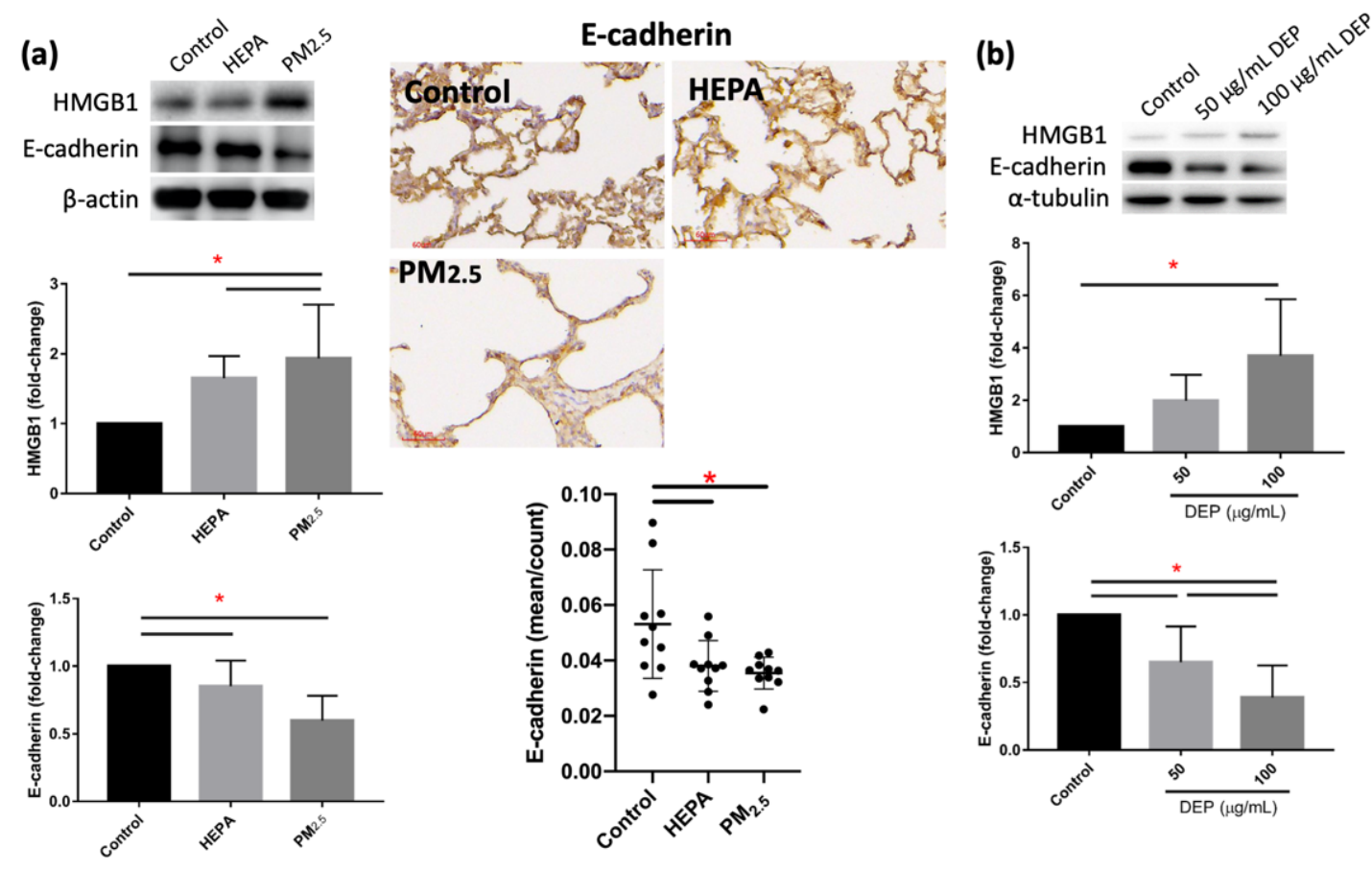

(c)
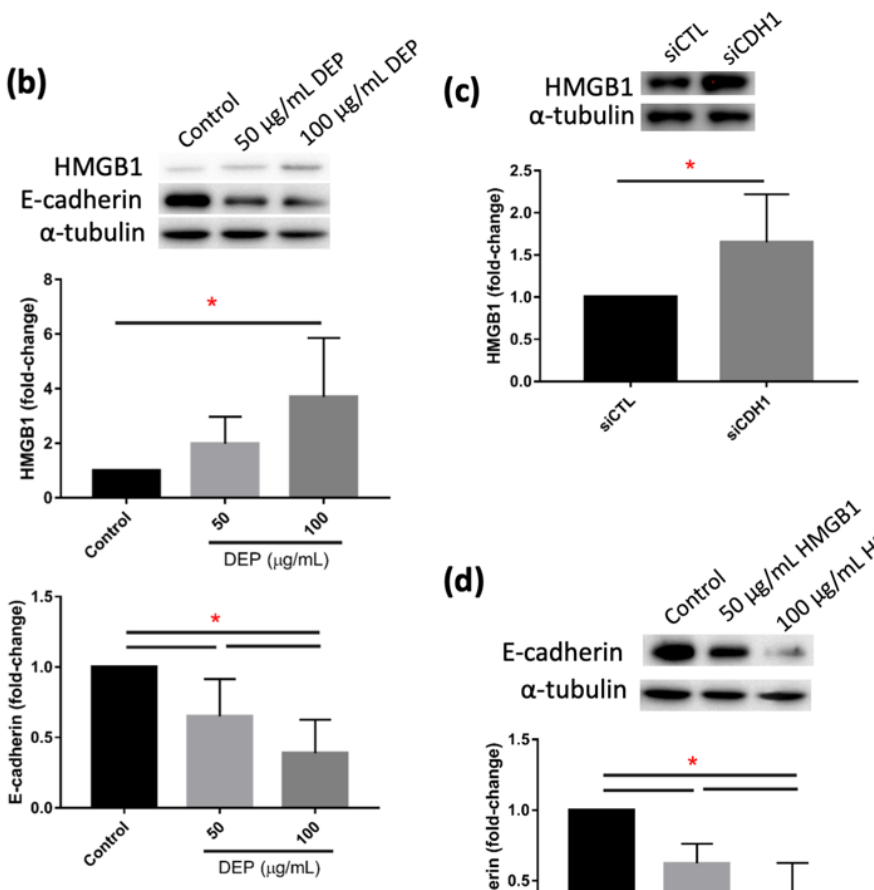

(d)

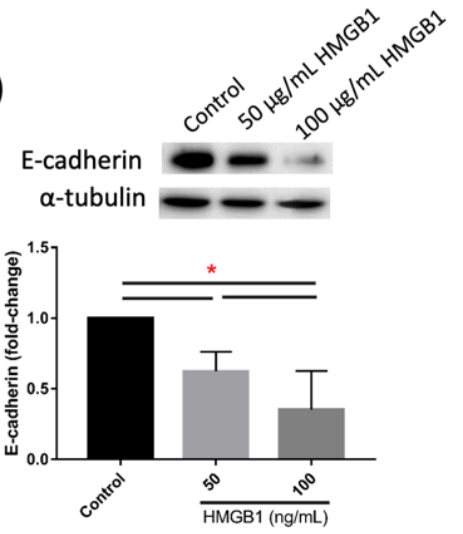

Figure 1

Expressions of high mobility group box 1 (HMGB1) and E-cadherin in the lungs due to air pollution. (a) Expressions of HMGB1 and E-cadherin in SD rats after 6 months of exposure to air pollution (HEPA for gaseous pollution and PM2.5; $n=8$ ). Protein expressions were examined in lung lysates, and H\&E staining was used to quantify protein expressions in alveolar regions. (b) Expressions of HMGB1 and E-cadherin by human alveolar epithelial A549 cells after exposure to 0,50, and $100 \mu \mathrm{g} / \mathrm{mL}$ diesel exhaust particles (DEPs) for $24 \mathrm{~h}(\mathrm{n}=6)$. (c) Expression of HMGB1 after E-cadherin (CDH1)-knockdown in A549 cells $(n=6)$. (d) Expression of E-cadherin after treatment with the HMBG1 recombinant protein at 0 (control), 50, and 100 $\mathrm{ng} / \mathrm{mL}$ in $\mathrm{A} 549$ cells for $24 \mathrm{~h}(\mathrm{n}=6) .{ }^{*} \mathrm{p}<0.05$. 
(a)
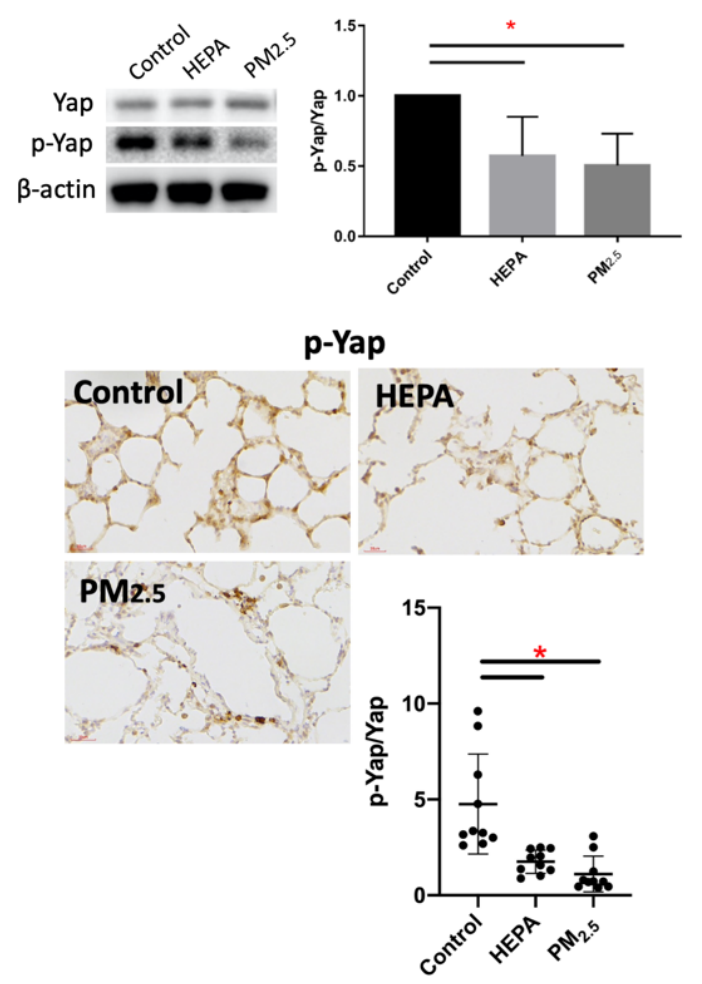

(b)

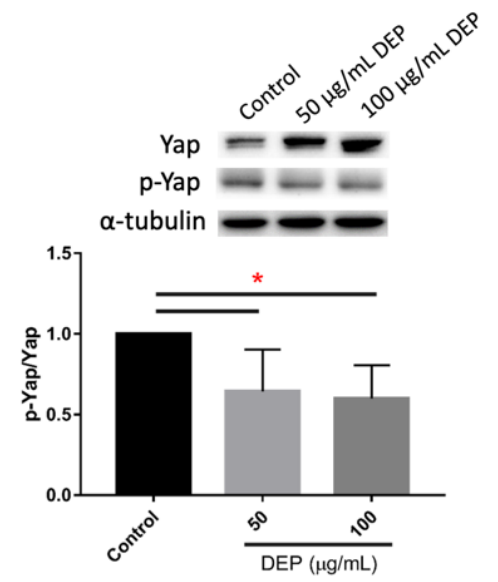

(c)

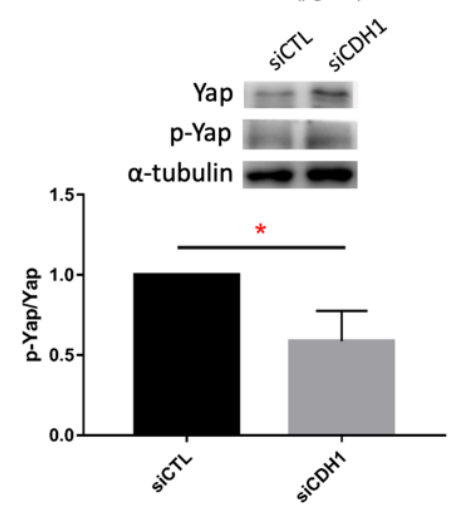

\section{Figure 2}

Expressions of Yap and phosphorylated (p)-Yap in the lungs after exposure to air pollution. (a) Expressions of Yap and $\mathrm{p}$-Yap in SD rats after 6 months of exposure to air pollution (HEPA for gaseous pollution and PM2.5; $n=8)$. $p$-Yap/Yap expressions were examined in lung lysates, and H\&E staining was used to quantify protein expressions in alveolar regions. (b) Expressions of $p-Y a p / Y a p$ by A549 cells after exposure to 0, 50, and $100 \mu \mathrm{g} / \mathrm{mL}$ of diesel exhaust particles (DEPs) for $24 \mathrm{~h}(\mathrm{n}=6)$. (c) Expressions of $\mathrm{p}$-Yap/Yap after Ecadherin (CDH1)-knockdown in A549 cells $(n=6) .{ }^{*} p<0.05$. 
(a)

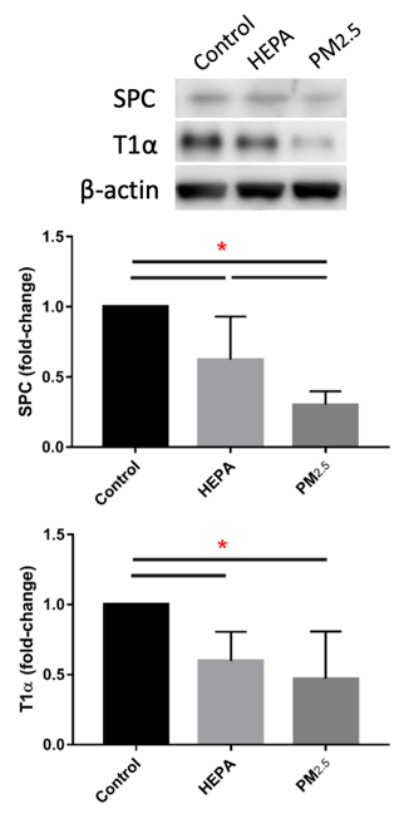

SPC
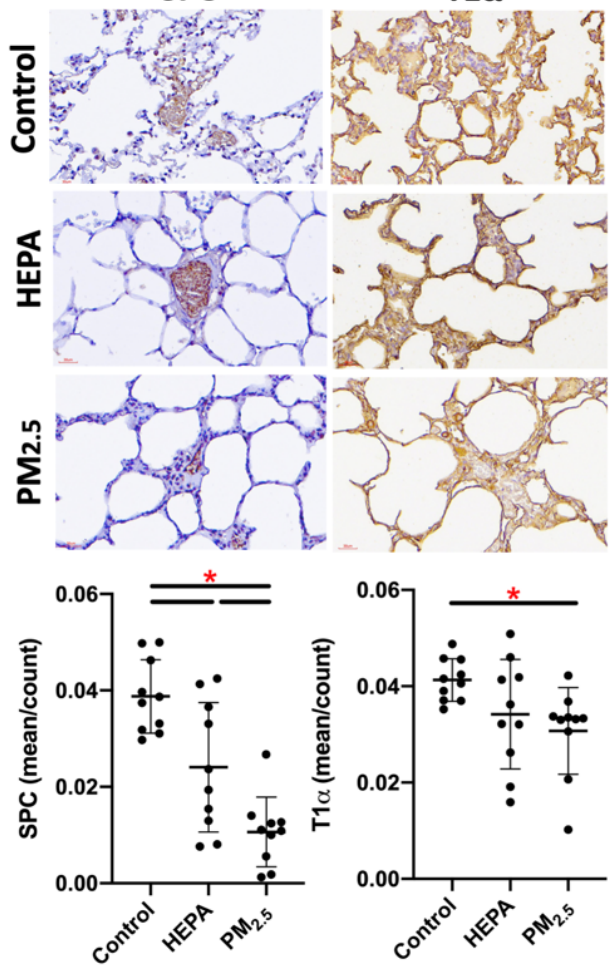

(b)
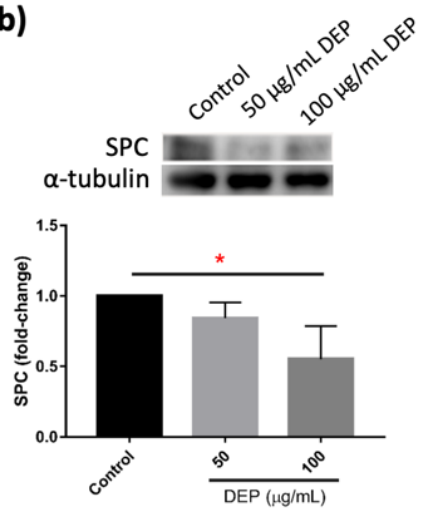

(c)
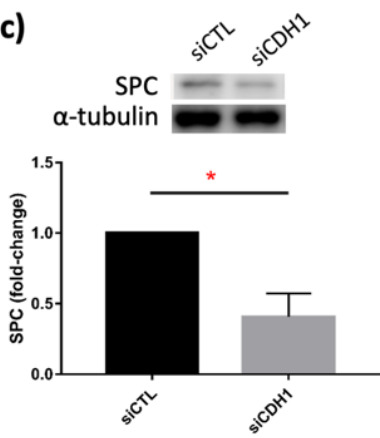

\section{Figure 3}

Expressions of SPC and T1a in the lungs after exposure to air pollution. (a) Expressions of SPC and T1a by SD rats after 6 months of exposure to air pollution (HEPA for gaseous pollution and PM2.5; $n=8$ ). SPC and T1a expressions were examined in lung lysates, and H\&E staining was used to quantify protein expressions in alveolar regions. (b) Expressions of SPC and T1a by A549 cells after exposure to 0, 50, and $100 \mu \mathrm{g} / \mathrm{mL}$ diesel exhaust particles (DEPs) for $24 \mathrm{~h}(\mathrm{n}=6)$. (c) Expressions of SPC and T1 a by E-cadherin (CDH1)knockdown in A549 cells $(n=6)$. * $p<0.05$. 
(a)

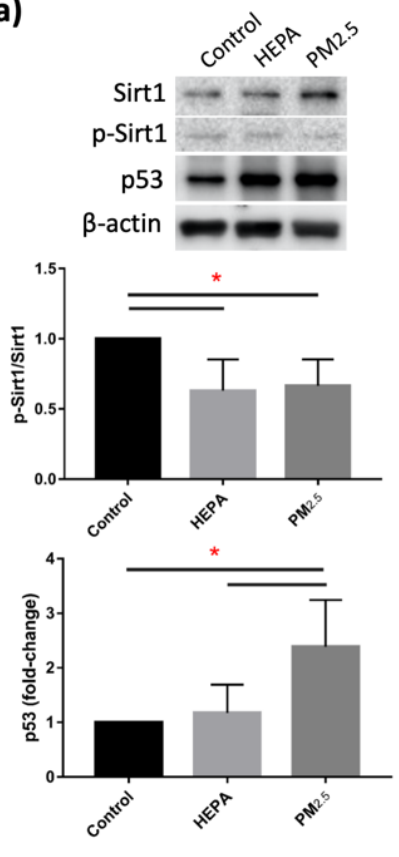

Sirt1
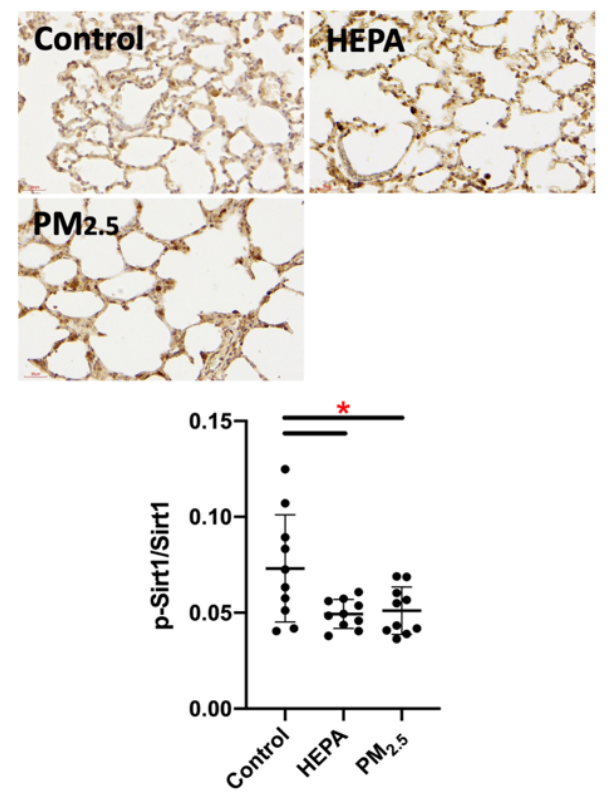

(b)
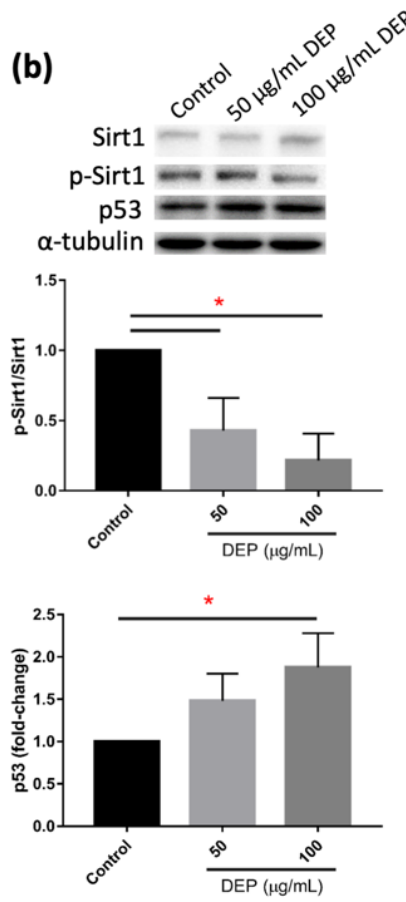

(c)

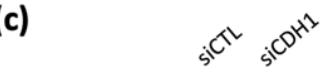

Sirt1 $\rightarrow-$

p-Sirt1 $=\pi$

p53 $\alpha$-tubulin
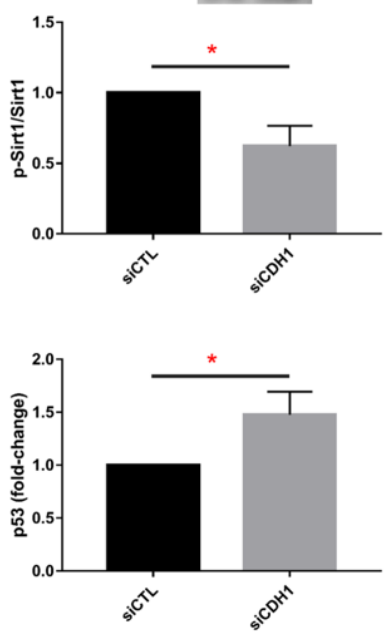

\section{Figure 4}

Expressions of Sirt1, phosphorylated (p)-Sirt1, and p53 in the lungs after exposure to air pollution. (a) Expressions of Sirt1, p-Sirt1, and p53 in SD rats after 6 months of exposure to air pollution (HEPA for gaseous pollution and PM2.5; n=8). p-Sirt1/Sirt1 and p53 expressions were examined in lung lysates, and H\&E staining was used to quantify $p$-Sirt1/Sirt1 expressions in alveolar regions. (b) Expressions of $p$ Sirt1/Sirt1 and p53 by A549 cells after exposure to 0,50, and $100 \mu \mathrm{g} / \mathrm{mL}$ diesel exhaust particles (DEPs) for $24 \mathrm{~h}(\mathrm{n}=6)$. (c) Expressions of p-Sirt1/Sirt1 and p53 after E-cadherin (CDH1)-knockdown in A549 cells ( $\mathrm{n}=6)$. $\star p<0.05$. 


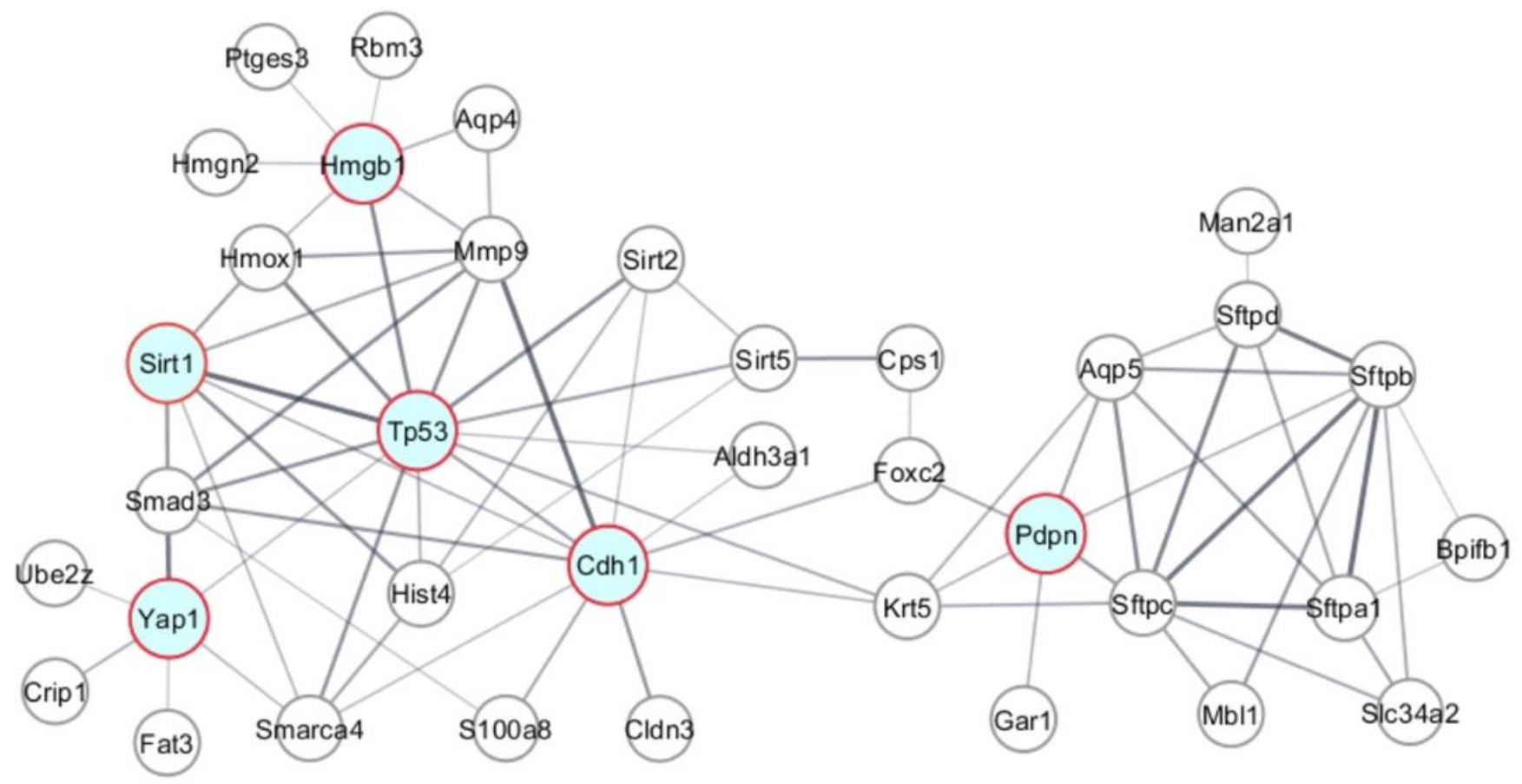

Figure 5

Protein-protein interaction network in the lungs of rats after exposure to air pollution. Interactions among these proteins in the lungs after air pollution exposure were identified by a proteomics approach.

(a)

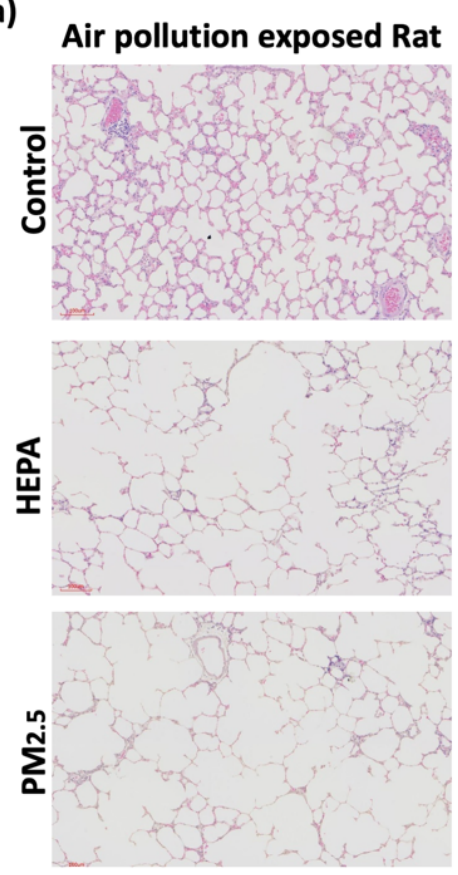

(b)

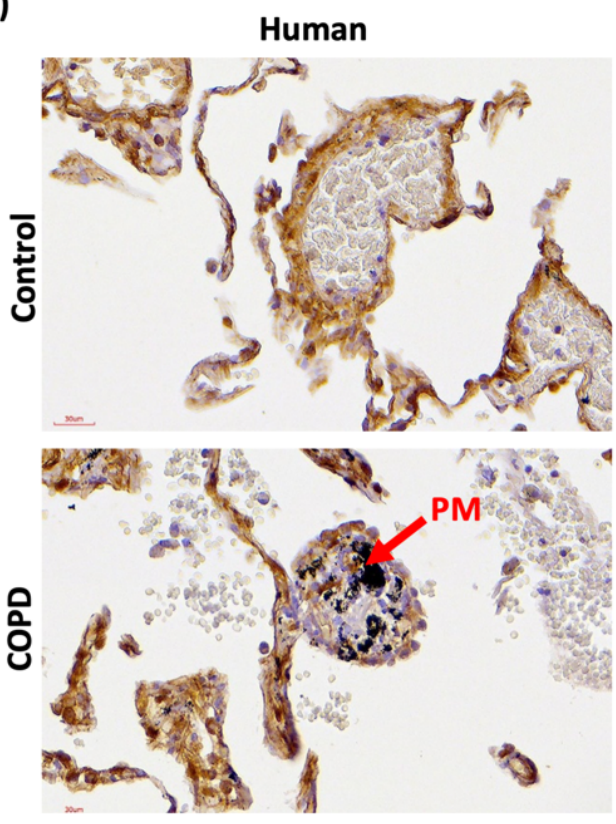

Figure 6 
(a) Emphysema in rats after 6 months of exposure to air pollution. (b) Particulate matter (PM) deposited in the lungs of chronic obstructive pulmonary disease (COPD) subjects (red arrow).

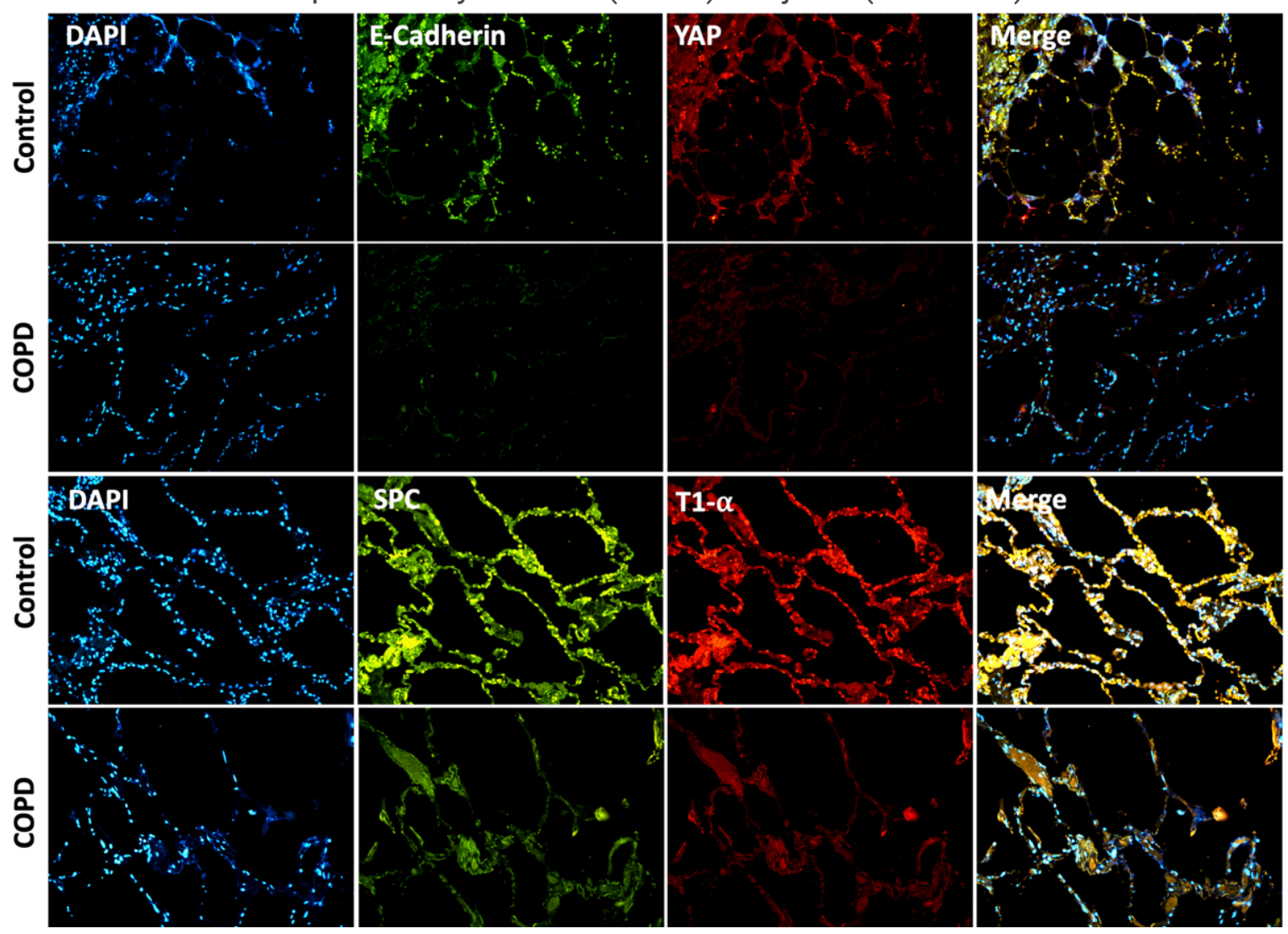

\section{Figure 7}

Expressions of E-cadherin, Yap, SPC, and T1a in alveolar regions of chronic obstructive pulmonary disease (COPD) subjects and control subjects by immunofluorescence (IF) staining. 